\title{
Neuroprotective Mechanisms of Lithium in Murine Human Immunodeficiency Virus-1 Encephalitis
}

\author{
Huanyu Dou, ${ }^{1,2}$ Brent Ellison, ${ }^{1}$ Jennifer Bradley, ${ }^{1,2}$ Alexander Kasiyanov, ${ }^{1,2}$ Larisa Y. Poluektova, ${ }^{1,2}$ Huangui Xiong, ${ }^{1,2}$ \\ Sanjay Maggirwar, ${ }^{4}$ Stephen Dewhurst ${ }^{4}$ Harris A. Gelbard, ${ }^{4}$ and Howard E. Gendelman ${ }^{1,2,3}$ \\ ${ }^{1}$ Center for Neurovirology and Neurodegenerative Disorders, ${ }^{2}$ Departments of Pharmacology and Experimental Neuroscience, and ${ }^{3}$ Department of Internal \\ Medicine, University of Nebraska Medical Center, Omaha, Nebraska 68198-5880, and ${ }^{4}$ The Center for Aging and Developmental Biology, Departments of \\ Neurology, Pediatrics, and Microbiology and Immunology, University of Rochester Medical Center, Rochester, New York 14642
}

Lithium (Li) has garnered considerable interest as a neuroprotective drug for a broad range of nervous system disorders. Its neuroprotective activities occur as a consequence of glycogen synthase kinase-3 $\beta$ (GSK-3 $\beta$ ) inhibition leading to downstream blockade of $\beta$-catenin and Tau phosphorylation. In the present study, we investigated Li-mediated neuroprotective mechanisms in laboratory and murine human immunodeficiency virus-1 (HIV-1) encephalitis (HIVE) models. In laboratory tests, Li protected neurons from neurotoxic secretions of HIV-1-infected monocyte-derived macrophages (MDMs). This neuroprotection was mediated, in part, through the phosphatidyl inositol 3-kinase/Akt and GSK-3 $\beta$ pathways. To examine the effects of Li treatment in vivo, MDMs were injected into the basal ganglia of severe combined immunodeficient mice and then Li was administered $(60 \mathrm{mg} / \mathrm{kg} / \mathrm{d})$. Seven days after MDM injection, mice were killed and CNS tissue was collected and subjected to immunocytochemical and Western blot assays for leukocyte and neural antigens, GSK-3 $\beta$, and key kinase substrates such as $\beta$-catenin and Tau. Numbers of HIV-1 p24 antigen-positive MDMs were unaltered by Li treatment of HIVE mice. Similarly, the greatly increased extent of astrocyte and microglia activation in HIVE mice (10-fold and 16-fold, respectively, compared with unmanipulated controls) was also unaltered by Li. In contrast, Li restored HIVE-associated loss of microtubule-associated protein-2-positive neurites and synaptic density while reducing levels or activity of phospho-Tau Ser ${ }^{202}$, phospho- $\beta$-catenin, and GSK-3 $\beta$. Electrophysiological recordings showed diminished long-term potentiation in hippocampal slices of HIVE mice that were restored by Li. Based on these data, the use of Li as an adjuvant for HIV-1-associated dementia is now being pursued.

Key words: HIV-1 encephalitis; lithium; neuroprotection; monocyte-derived macrophages; glycogen synthase kinase-3 $\beta$; neurodegeneration

\section{Introduction}

Lithium ( $\mathrm{Li})$ is a neuroprotective agent with known antiapoptotic activities affecting phosphatidylinositol 3 (PI3)-kinase (PI3-K)/Akt and mitogen-activated protein kinase cell-signaling pathways (Chalecka-Franaszek and Chuang, 1999; Mora et al., 1999; Zorrilla Zubilete, 2003) and, importantly, potent inhibitory activity directed against glycogen synthase kinase- $3 \beta$ (GSK-3 $\beta$ ) inhibition (Chalecka-Franaszek and Chuang, 1999; Harwood and Agam, 2003; Berry et al., 2004). Collectively, these kinases stimulate the phosphorylation and aberrant assembly of neuronal microtubule-associated protein (MAP) Tau (Hernandez et al., 2003). Ultimately, Li-induced inhibition of GSK-3 $\beta$ affects a wide range of downstream effectors that mediate both antiapoptotic and proapoptotic pathways, including $\beta$-catenin, heat

Received Jan. 8, 2005; revised June 24, 2005; accepted July 25, 2005.

This work was supported by National Institutes of Health Grants P01 NS31492 (H.E.G.), R01 NS34239 (H.E.G.), P01 NS43985 (H.E.G.), R37 NS36136 (H.E.G.), and P01 MH64570 (H.A.G., S.D., S.M., and H.E.G.). We thank Robin Taylor (University of Nebraska Medical (enter) for excellent graphic and administrative assistance and Ziye Sui and Elizabeth Reisinger (University of Rochester Medical Center) for excellent technical support.

Correspondence should be addressed to Dr. Howard E. Gendelman, Center for Neurovirology and Neurodegenerative Disorders, University of Nebraska Medical Center, Omaha, NE 68198-5880. E-mail: hegendel@unmc.edu. DOI:10.1523/JNEUROSCI.2164-05.2005

Copyright $\odot 2005$ Society for Neuroscience $\quad 0270-6474 / 05 / 258375-11 \$ 15.00 / 0$ shock factor 1, activator protein 1, cAMP response elementbinding protein, and Bcl-2 (Hokin et al., 1996; Jope and Bijur, 2002; Li et al., 2002; Tyson et al., 2002; Kim et al., 2003; Brunello, 2004). Although widely used in the treatment of bipolar mood disorder (Jope, 1999), interest in Li has now extended into its potential use for a wide range of environmental and neurodegenerative insults (Jope, 1999; Zorrilla Zubilete, 2003; Song et al., 2004). Other potential neuroprotective mechanisms induced by $\mathrm{Li}$ include induction of brain-derived neurotrophic factor (BDNF) and proapoptotic responses mediated through NMDA receptor engagement and calcium regulation (ChaleckaFranaszek and Chuang, 1999; Harwood and Agam, 2003; Berry et al., 2004). These observations support the idea that the neuroprotective activities of Li may be translated into effective treatments of a range of neurodegenerative diseases (Hashimoto et al., 2003a,b), including, perhaps, human immunodeficiency virus-1 (HIV-1)-associated dementia (HAD).

To this end, we tested whether Li could protect neurons in laboratory assays and in an animal model of HIV-1 encephalitis (HIVE), the pathological correlate of HAD. We raised the question of whether Li could ameliorate HIV-1-associated neurodegeneration. Because HIV-1-mediated neuronal injury stimulates GSK-3 $\beta$, we assessed whether inhibition of this pathway by Li 
would be a potential mechanism for drug action. We show that $\mathrm{Li}$ treatment protects both rodent and human neurons from the neurotoxic effects of HIV-1-infected monocyte-derived macrophages (MDMs) in vitro. Also, Li treatment of severe combined immunodeficient disease (SCID) HIVE mice results in neuronal protection and induction of neurogenesis in the dentate gyrus (DG). We further demonstrate that Li protects against HIV-1 neurotoxicity by diminishing neuronal apoptosis and protecting synaptic density and dendritic arbor through GSK-3 $\beta$ inhibition and activating the PI3-kinase/Akt cell-signaling pathways. Because phosphorylation and assembly of tau are linked to HIV-1associated neurodegeneration, the inhibition of GSK-3 $\beta$ and reduction in $\beta$-catenin and Tau phosphorylation provide a mechanism for how Li could elicit positive clinical outcomes and support its possible future use as an adjunctive therapy for HAD.

\section{Materials and Methods}

Isolation and HIV-1 infection of MDMs. Human monocytes were recovered from peripheral blood mononuclear cells of HIV-1, HIV-2, and hepatitis B virus seronegative donors after leukopheresis and purified by counter-current centrifugal elutriation (Gendelman et al., 1988). Monocytes were cultured in DMEM (Sigma, St. Louis, MO) supplemented with $10 \%$ heat-inactivated human serum, 2 mM L-glutamine, gentamicin (50 $\mu \mathrm{g} / \mathrm{ml})$, ciprofloxacin $(10 \mu \mathrm{g} / \mathrm{ml})$, and macrophage colonystimulating factor $(1000 \mathrm{U} / \mathrm{ml}$; a generous gift from Genetics Institute, Cambridge, MA). Monocytes were cultivated for $7 \mathrm{~d}$ and then referred to as MDMs. MDMs were infected with $\mathrm{HIV}-1_{\mathrm{ADA}}$ (a macrophage tropic viral strain) at a multiplicity of infection (MOI) of 0.01 .

Human fetal neurons. Human fetal brain tissue (gestational age, 13-16 weeks) was obtained from elective abortions in full compliance with the University of Nebraska Medical Center and National Institutes of Health ethical guidelines. Cells were plated in poly-lysine-coated 24-well plates (BD Biosciences, San Diego, CA) at a density of $5 \times 10^{5}$ cells/well. Cells were cultured in Neurobasal media (Invitrogen, Rockville, MD) supplemented with B27 (Invitrogen). At $5 \mathrm{~d}$ after cell culture, $10 \mu \mathrm{g} / \mathrm{ml}$ 5-fluorodeoxyuridine was added to inhibit proliferation of dividing cells (astrocytes/fibroblasts). The purity of neural cell preparations was assayed by immunocytochemical methods as described below. At 2 weeks after cell cultivation, $>70 \%$ of the neuronal-enriched preparations were MAP-2 immunopositive.

HIV-1-associated neurotoxicity and neuroprotection. Human fetal neurons were cultivated for 2 weeks and then exposed to culture fluids of uninfected (control) and HIV-1-infected MDM [25\% (v/v)] for $5 \mathrm{~d}$ in the presence or absence of lithium chloride (Li; $10 \mathrm{~mm}$; Sigma). 2-(4morpholinyl)-8-phenyl-1(4 H)-benzopyran-4-one [LY294002 (LY); 50 $\mu \mathrm{M}$; EMD Biosciences, San Diego, CA], indirubin- $3^{\prime}$-monoxamine (Ind; $10 \mu \mathrm{M}$; Sigma), K252a (100 nм; Calbiochem, La Jolla, CA), or myoinositol (Ino; $10 \mu \mathrm{M}$; EMD Biosciences) were added to HIV-1-exposed cultures. Cells were fixed with $4 \%$ paraformaldehyde and subjected to assays of neuronal apoptosis, measures of neuronal dendrites, and synaptic processes.

Neuronal apoptosis. Terminal deoxynucleotidyl transferase-mediated biotinylated UTP nick end labeling (TUNEL) staining was performed using the in situ cell death detection kit, TMR Red (Roche Diagnostic, Indianapolis, IN), following the protocol of the manufacturer. Apoptotic cells were identified with TUNEL, which detects the DNA fragmentation characteristic of apoptotic cells. The cells were viewed under a fluorescence microscope, and the total numbers of bright green nuclei in each field were counted. Using the same field of view, $4^{\prime}, 6^{\prime}$-diamidino-2phenylindole (DAPI) nuclei staining was used to normalize the data retrieved for neuronal apoptosis. This resulted in a neuronal apoptosis index that was calculated by dividing the number of counted TUNELpositive green by total DAPI-positive cells.

Immunocytochemical analyses of neural injury. Primary human fetal neurons were cultured for 2 weeks. Twenty-five percent (v/v) of culture fluids from MDMs infected with HIV- $1_{\mathrm{ADA}}$ at an MOI of 0.01 for $7 \mathrm{~d}$ were prepared. These fluids contained $5 \times 10^{6} \mathrm{cpm} / \mathrm{ml}$ reverse transcrip- tase activity. The virus-infected MDM fluids were then added to neurons for an additional $5 \mathrm{~d}$ with Ind $(10 \mu \mathrm{M})$ alone or LY $(50 \mu \mathrm{M}), \mathrm{K} 252 \mathrm{a}(100$ $\mathrm{nM})$, and Ino $(10 \mu \mathrm{M})$ in the absence or presence of $\mathrm{Li}(10 \mathrm{~mm})$. The culture media was removed, and the neuronal cells were fixed with methanol/acetone $(1: 1)$ for $10 \mathrm{~min}$ at $-20^{\circ} \mathrm{C}$. The cells were treated with antibodies against MAP-2 and synaptophysin (SYP) (both from Chemicon, Temecula, CA) or glial fibrillary acidic protein (GFAP) (Dako, High Wycombe, UK), respectively, overnight and then washed with PBS and incubated for $1 \mathrm{~h}$ with FITC-labeled secondary antibodies (Boehringer Mannheim, Indianapolis, IN). Histocytochemical tests were examined with a Nikon (Tokyo, Japan) Microphot-FXA microscope. For the quantitation of immunoreactive cells, 15 randomly selected fields were analyzed.

SCID mouse model of HIVE. Four-week-old male C.B.-17 SCID mice were purchased from The Jackson Laboratory (Bar Harbor, ME). Animals were maintained in sterile microisolator cages. One day after infection, HIV- $1_{\mathrm{ADA}}$-infected MDMs $\left(5 \times 10^{5}\right.$ cells in $\left.5 \mu \mathrm{l}\right)$ were injected intracranially. Li was administered $(60 \mathrm{mg} / \mathrm{kg} / \mathrm{d}) 1 \mathrm{~d}$ after injection. Control animals were left untreated. All animals were killed at day 7 (peak of inflammation and neuronal injury).

Histopathology and image analysis. Brain tissue was collected at necropsy, fixed in $4 \%$ phosphate-buffered paraformaldehyde, and embedded in paraffin or frozen for later use. Blocks were cut to identify the injection site. For each mouse, 30-100 serial (5- $\mu \mathrm{m}$-thick) sections were cut from the injection site and at the level of the hippocampus. Immunohistochemical staining followed a basic indirect protocol. Alternatively, brains were frozen after fixation, and $30 \mu \mathrm{m}$ sections were prepared for immunofluorescent staining. Antibodies to vimentinintermediate filaments (clone 3B4; Dako) were used for detection of human cells in the mouse brain. Murine microglia were identified by Griffonia simplicifolia lectin I-isolectin. Astrocytes were identified using antibodies specific for GFAP. Neuron-specific nuclear protein (NeuN), MAP-2, and SYP were used for neuronal detection. Antibodies to HIV-1 p24 antigen (Dako) were applied to determine the number of HIV-1infected cells. Immature neurons were localized by antibodies by polysialylated neuronal cell adhesion molecules (PSA-NCAMs; mouse IgM; generously provided by Dr. T. Seki, Jutendo University School of Medicine, Tokyo, Japan). All paraffin-embedded sections were counterstained with Mayer's hematoxylin. Deletion of primary antibody served as a control. Tissue examination was performed with an Eclipse E800 microscope (Nikon Instruments, Melville, NY). Images were obtained by an Optronics (Buffalo Grove, IL) digital camera with MagnaFire (Goleta, CA) 2.0 software and processed by Adobe Photoshop 7.0 software (Adobe Systems, San Jose, CA). Quantification of immunostaining was done using Image-Pro Plus (version 4.0) on serial coronal brain sections.

Western blot assays. Primary human fetal neuronal cultures were prepared as described above. Virus-infected MDM fluids were added to neurons with LY $(50 \mu \mathrm{M})$, Ind $(10 \mu \mathrm{M})$, and K252a (100 nM) with or without $\mathrm{Li}(10 \mathrm{~mm})$ for $2 \mathrm{~h}$. Protein lysates were prepared and electrophoretically separated on SDS-PAGE and transferred onto polyvinyldifluoridene membranes. Membranes were incubated with primary antibodies to antibody $\beta$-catenin, phospho- $\beta$-catenin $\operatorname{Ser}^{33,37}$ (both from Sigma), GSK-3 $\beta$ (BD Biosciences), phospho-GSK-3 $\beta$ serine 9 (Ser $\left.{ }^{9}\right)$ (Affinity BioReagents, Golden, CO), and $\beta$-tubulin (Promega, Madison, WI). Two-millimeter SCID mice brain sections that included the site of injection were used for extraction of proteins. Tissue sections corresponding to the site of injection in the contralateral hemisphere served as controls. The brain was homogenized in lysis buffer containing $50 \mathrm{~mm}$ Tris-HCl, pH 7.4, $150 \mathrm{~mm} \mathrm{NaCl,} 2$ mм EDTA, 1\% NP-40, aprotinin, bestatin, leupeptin, pepstatin A, aminoethyl benzenesulfonylfluoride, and E-64. Proteins were electrophoretically separated on SDS-PAGE and transferred onto polyvinyldifluoridene membranes. Membranes were incubated with primary antibodies to Tau5 (BD Biosciences), phosphoTau Ser ${ }^{202}$ (Sigma), $\beta$-catenin, phospho- $\beta$-catenin Ser ${ }^{33,37}$, GSK-3 $\beta$, MAP-2, and $\beta$-tubulin. Horseradish peroxidase-conjugated secondary antibodies were used, and membranes were treated with chemiluminescent substrate and then exposed to $\mathrm{x}$-ray film. Images were digitized with a densitometer (Molecular Dynamics, Sunnyvale, CA), and protein levels 
A

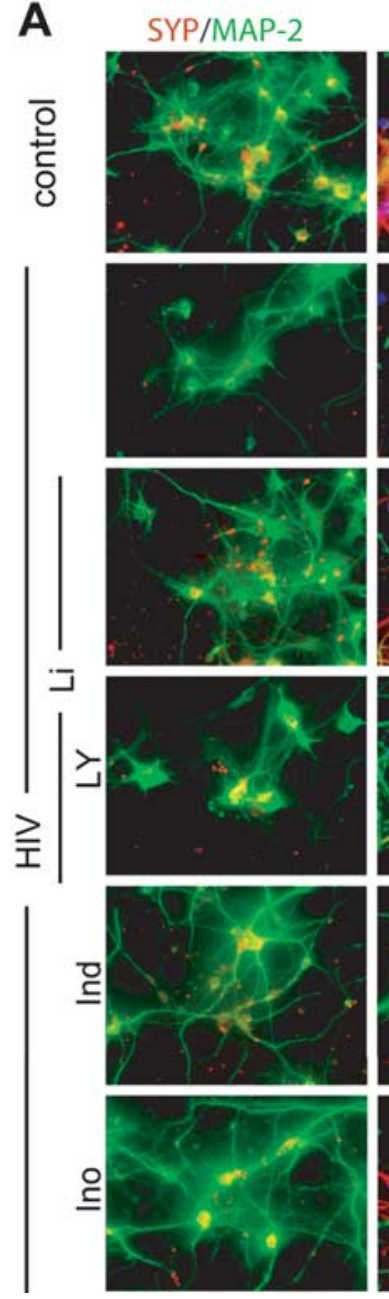
MAP-2/GFAP
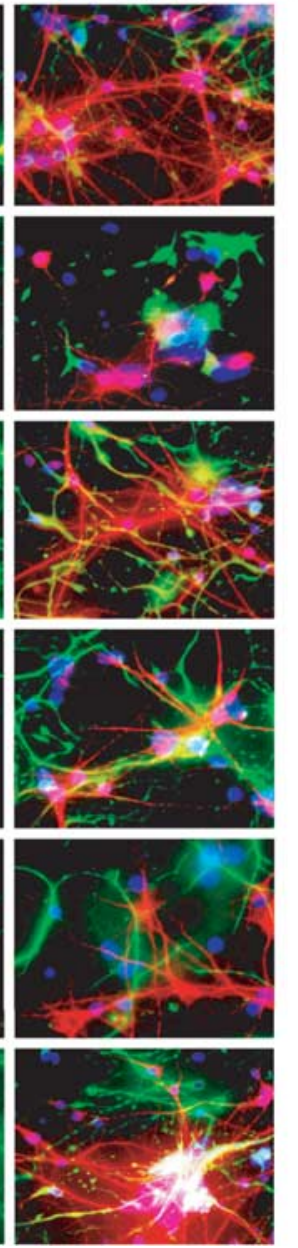

B

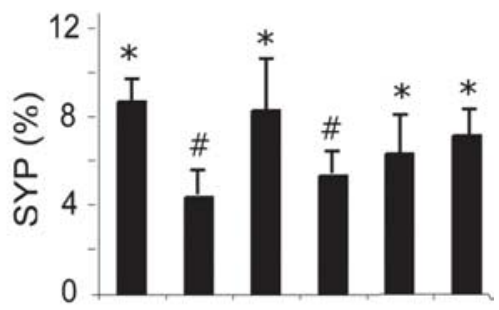

C

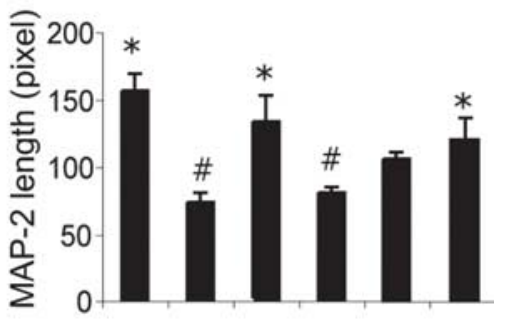

D

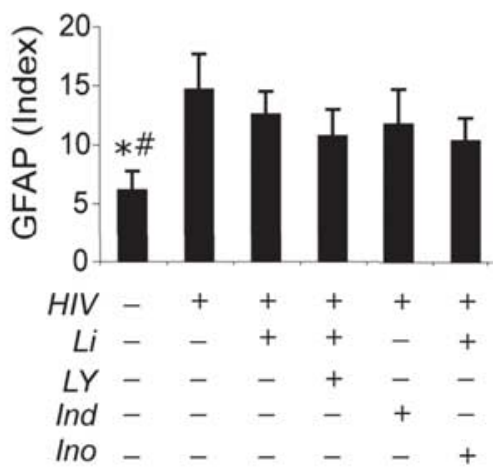

Figure 1. Li protects human fetal neurons against toxicity of culture fluids from HIV-1-infected MDMs. Human fetal neurons were cultivated for 2 weeks and then exposed to culture fluids of uninfected (control) and HIV-1-infected MDM [25\% (v/v)] for $5 \mathrm{~d}$ in the presence or absence of $\mathrm{Li}(10 \mu \mathrm{m}$; as indicated), after which the cultures were analyzed by immunostaining. $\operatorname{LY}(50 \mu \mathrm{M})$, Ind $(10 \mu \mathrm{m})$, and Ino $(10 \mu \mathrm{m})$ were added at the time of neuronal exposure to the HIV-1 ${ }^{+}$fluids. $\boldsymbol{A}$, Fluorescent images show immunoreactivity for MAP-2 (left, green; right, red), SYP (left, red), and GFAP (right, green). This analysis revealed a high density of dendritic nodes and long neuritic processes with prominent cell bodies and synaptic staining in control neurons. Diminished dendritic nodes, short neurites, and loss of processes were apparent in neurons treated with HIV- ${ }^{+}$fluids and were reversed by $\mathrm{Li}$ (right). In addition, extensive astrogliosis (reflected by prominent GFAP immunoreactivity) was detected in all cultures exposed to HIV-1 ${ }^{+}$fluids. Quantitative analysis of these immunostaining results are presented for synaptophysin (B), MAP-2 (C), and GFAP (D). SYP expression $(p<0.01)$ and MAP- $2^{+}$neurite length $(p<0.003)$ were reduced in neurons treated with HIV-1 ${ }^{+}$fluids compared with untreated control cultures. In Li-treated cultures, the expression of SYP and MAP-2 was essentially restored ( $p<$ 0.05 and $p<0.004$, respectively) when compared with untreated HIV-1 ${ }^{+}$neurons. LY added to HIV- $1^{+}$fluid-exposed cultures in the presence of Li blocked the neuroprotective effects of Li on SYP and MAP-2 expression ( $p<0.05$ and $p<0.01$, respectively). As a GSK-3 inhibitor, Ind also induced neuroprotective activities, parallel to what was observed when supplied to cells exposed to HIV-1 ${ }^{+}$fluids (SYP, $p<0.03$; MAP-2, $p=0.055$ ). Additional $10 \mu \mathrm{M}$ Ino added to Li-treated HIV- ${ }^{+}{ }^{+}$-exposed neurons had no effect on Li neuroprotection. These results are representative of three individual experiments performed in quadruplicate determinations. Original magnification, $400 \times$. The asterisk denotes a statistically significant difference when compared with cells that receive HIV-1 ${ }^{+}$fluids; the number sign denotes a statistically significant difference compared with cultures that were exposed to HIV $-1^{+}$fluids in the presence of Li.

were expressed as a ratio to $\beta$-tubulin. Data were analyzed using Microsoft (Redmond, WA) Excel with Student's $t$ test for comparisons. All statistics are presented as mean \pm SEM.

Electrophysiological tests. Seven days after injection, brains were quickly removed from the cranial cavities. The ipsilateral and contralateral of hippocampi were separated and placed in ice-cold $\left(4^{\circ} \mathrm{C}\right)$ oxygenated artificial CSF before sectioning. The ability of high-frequency stimulation (HFS) to induce long-term potentiation (LTP) in the CA1 region of the hippocampus was examined after a $20 \mathrm{~min}$ control recording. LTP was induced by weak tetanic stimulation (10 events at $100 \mathrm{~Hz}$ ) observed for $60 \mathrm{~min}$ as described previously (Anderson et al., 2003). Results from slices with large fluctuation $(>2$ SDs) were rejected.

\section{Results}

Li protects neurons after exposure to HIV-1-infected MDM fluids

We investigated whether $\mathrm{Li}$ protects primary human fetal neurons after exposure to culture fluids from HIV-1-infected MDM (Fig. 1). In these experiments, cells were treated with fluids from uninfected (control) and HIV-1-infected MDM $\left[25 \%(\mathrm{v} / \mathrm{v})\left(\mathrm{HIV}-1^{+}\right)\right]$in the absence or presence of $10 \mathrm{~mm}$ Li for $5 \mathrm{~d}$. Li effects on synapse formation were then examined, and representative results are shown in photomicrographs of cultured cells stained with antibodies to SYP (Fig. 1, red) and MAP-2 (Fig. 1, green) (Fig. $1 \mathrm{~A}$, left column). SYP, a major integral membrane glycoprotein, is expressed in abundance in presynaptic vesicles of neurons; SYP immunostaining was found to be punctated in MAP-2 ${ }^{+}$dendrites. Quantitative analysis of SYP expression in 12 random fields of view (Fig. $1 B$ ) showed diminished staining in neurons treated with $\mathrm{HIV}-1^{+}$ culture fluids $(p<0.01)$. However, in Litreated neurons that were exposed to HIV $-1^{+}$culture fluids, the distribution and staining "intensity" of SYP was essentially restored (Fig. $1 A, B)(p<0.05)$.

We compared SYP immunostaining data to those obtained for MAP-2. MAP- $2^{+}$dendrites (Fig. $1 A$ ) were readily detected in primary human neuronal cells. These were measured by quantitative image analysis to quantitate neurite length (Fig. 1C). $\mathrm{HIV}-1^{+}$culture fluids induced significant decreases in MAP-2 immunostaining and $\mathrm{MAP}-2^{+}$neurite length in primary neurons when compared with untreated controls $(p<0.003)$; these changes were mostly reversed in the presence of $\mathrm{Li}$, which increased the numbers and density of MAP- $2^{+}$neurites, compared with untreated controls $(p<$ 0.004). Moreover, connections among neurites were also increased when staining results were compared with cultures treated with $\mathrm{HIV}-1^{+}$fluids alone (Fig. $1 A, C)$. Importantly, the neuroprotective effects of $\mathrm{Li}$ in this neuronal culture system occurred in the absence of effects on astrocyte activation. HIV- ${ }^{+}$fluids induced extensive astrogliosis, as reflected by a strong increase in GFAP immunostaining (Fig. $1 A, D)$, and this was unaltered by the addition of Li. Thus, Li exerted its neuroprotective effects through direct action(s) on neurons.

To investigate the mechanism(s) whereby Li might be exerting its effects, we performed additional studies designed to examine the role of specific signaling pathways that have been linked to the 
effects of Li in other experimental systems. We first focused on the GSK-3 $\beta$ pathway and examined the neuroprotective efficacy of a highly specific GSK-3 $\beta$ inhibitor, Ind. As shown in Figure 1, Ind elicited a very similar neuroprotective response to Li. Next, we explored the role of inositol monophosphatase in Li-mediated neuronal protection. Because Li inhibits inositol monophosphatase (Klein and Melton, 1996; Maggirwar et al., 1999) and could deplete cells of an endogenous source of inositol, replicate experiments were performed in which we treated cells with $\mathrm{Li}$ in the presence of an exogenous source of inositol (myo-inositol; denoted as Ino in Fig. 1) to ascertain its effects on neuronal protection. Such experiments demonstrated no significant changes in Li-mediated neuroprotection after addition of $10 \mu \mathrm{M}$ Ino, and neuroprotection was seen at levels equivalent to what was observed with Li alone (Fig. $1 A-C$ ).

We also examined whether the PI3-K/Akt signaling pathway might contribute to Li-mediated neuroprotection. To do this, cells were exposed to HIV-1 ${ }^{+}$culture fluids in the presence of either Li alone or Li plus the potent PI3-K inhibitor LY294002. This revealed that the neuroprotective effects of Li were blocked by LY, resulting in diminished SYP staining and MAP $-2^{+}$neurites $(p<0.05$ and $p<0.01)$ when compared with $\mathrm{HIV}-1^{+}$ fluid-exposed cultures that were treated with Li alone. Together, we demonstrate that $\mathrm{Li}$ protects the neuronal cytoskeleton (MAP-2) and promotes neurite outgrowth through inhibition of GSK-3 and activation of PI3-K/Akt pathways. Li also stabilizes SYP and may engage PI3-related mechanisms, but at reduced levels.

\section{Li-mediated protection of HIV-1-mediated apoptotic cell death}

We next analyzed whether Li affects neuronal apoptosis induced by $\mathrm{HIV}-1^{+}$fluids in human fetal neurons. To do this, neuronal apoptosis was quantitated by combined TUNEL/DAPI staining (Fig. 2) in cultures exposed to $\mathrm{HIV}-1^{+}$fluids for $5 \mathrm{~d}$ in the presence or absence of $\mathrm{Li}$. In replicate experiments, specific inhibitors of key pathways that are regulated by Li were added (Fig. 2). We focused on tyrosine receptor kinase (Trk) signaling (inhibited by K252a) (Fig. 2A), PI3-K/Akt activation (blocked by LY) (Fig. $2 B$ ), GSK-3 $\beta$ activation (prevented by Ino) (Fig. $2 C$ ), and inositol monophosphatase (IMPase) inhibition (functionally reversed by the addition of exogenous myo-inositol) (Fig. 2D). The percentage of TUNEL-positive cells from three independent experiments is shown in Figure 2. Vehicle (control) cultures showed few TUNEL-positive neurons, whereas cultures treated with $\mathrm{HIV}-1^{+}$fluids showed large numbers of neurons undergoing apoptosis $(p<0.001)$. In contrast, neurons that were exposed to culture fluids from HIV-1-infected MDMs in the presence of 10 $\mathrm{mM} \mathrm{Li}$ showed a dramatic decrease in the numbers of apoptotic cells $(p<0.003)$.

To investigate the mechanisms of Li-mediated neuroprotection, we used specific inhibitors of four key pathways known to be impacted by Li. K252a, a Trk inhibitor, reversed in part the neuroprotective effect of $\mathrm{Li}$ treatment, resulting in an increase in TUNEL staining similar to what was found in Li-treated neurons ( $p=0.063)$. Treatment with K252a alone did not affect neuronal TUNEL staining (data not shown). These results suggested that $\mathrm{Li}$ neuroprotection could be independent of the TrkB signaling pathway. We next tested whether the PI3-kinase/Akt pathway was operative in Li neuroprotective activities. The PI3-kinasespecific inhibitor LY was added to Li-treated neurons exposed to $\mathrm{HIV}-1^{+}$fluids. LY attenuated the neuroprotective effectiveness of Li (Fig. $2 B)(p<0.02)$. To determine whether GSK-3 $\beta$ inhi-

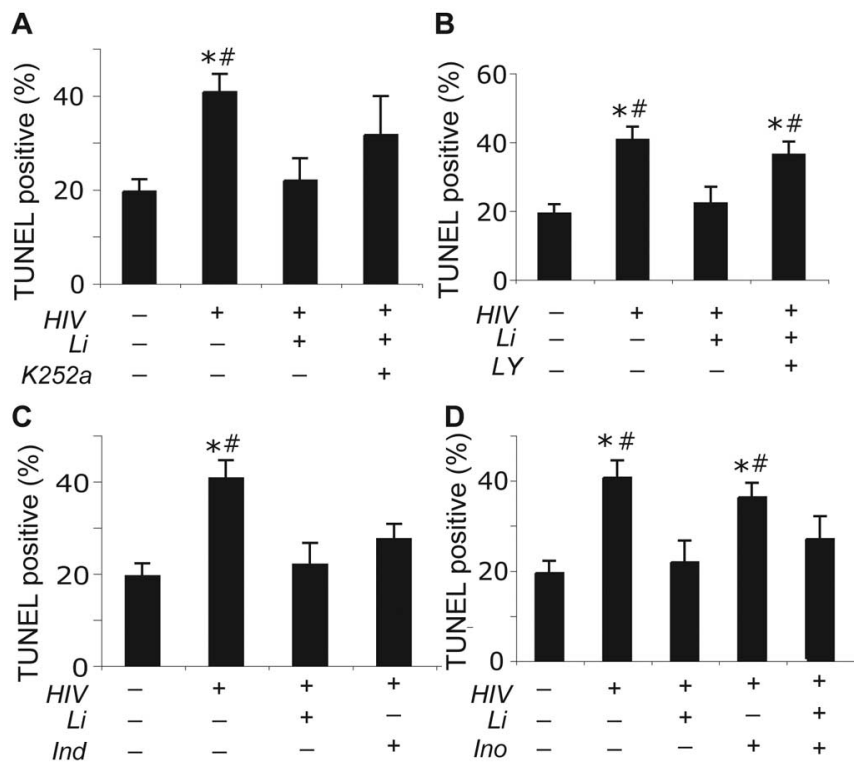

Figure 2. Quantitative measures of neuronal apoptosis link specific cell-signaling pathways and Li-mediated neuroprotection. Human fetal neurons were cultivated for 2 weeks and then exposed to culture fluids of HIV-1-infected MDM [25\% (v/v)] for $5 \mathrm{~d}$. In the presence or absence of Li $(10 \mathrm{~mm}), \mathrm{LY}(50 \mu \mathrm{M})$, Ind $(10 \mu \mathrm{M}), \mathrm{K} 252 \mathrm{a}(100 \mathrm{~nm})$, and Ino $(10 \mu \mathrm{m})$ were added at the time of neuronal exposure to the HIV-1 ${ }^{+}$fluids. Uninfected MDM culture fluids served as controls. The levels of neuronal apoptosis were measured by TUNEL with normalization by DAPI staining. Increased apoptosis was observed in neurons treated with HIV-1 ${ }^{+}$fluids compared with untreated control cultures $(p<0.001)$. This was reversed by Li $(p<0.003)$. $\boldsymbol{A}$, The TrkB inhibitor K252a failed to statistically alter TUNEL staining in all treatment groups. The PI3-kinase/Akt pathway was reflected by LY. $B$, LY added to Li-treated neurons exposed to HIV- ${ }^{+}$fluids prevented Li-induced reductions in TUNEL staining $(p<0.02)$. C, The GSK-3 $\beta$ inhibitor Ind had effects similar to those observed for $L i$. Ind reduced the levels of apoptosis in neurons exposed to HIV-1 ${ }^{+}$culture fluids when compared with neurons treated with HIV-1 fluids alone ( $p<$ 0.05). $\boldsymbol{D}$, Ino added to Li-treated neurons exposed to HIV- ${ }^{+}$fluids showed similar TUNEL levels as Li administration alone ( $p=0.114$ ). These results are representative of three individual experiments performed in quadruplicate determinations. Original magnification, $400 \times$. The asterisk denotes a statistically significant difference when compared in a pairwise manner with untreated control cells that did not receive HIV-1 ${ }^{+}$fluids; the number sign denotes a statistically significant difference compared with cultures that were exposed to HIV-1 ${ }^{+}$fluids in the presence of $\mathrm{Li}$.

bition might contribute to Li-mediated neuroprotection, a specific GSK-3 $\beta$ inhibitor (Ind) was added to neurons exposed to $\mathrm{HIV}-1^{+}$fluids. Ind diminished neuronal apoptosis induced by $\mathrm{HIV}-1^{+}$fluids when administered in the absence of Li (Fig. 2C) $(p<0.05)$. These findings indicate that specific inhibition of GSK-3 $\beta$ can protect neurons from HIV-1 MDM-mediated apoptosis and that $\mathrm{Li}$ and Ind both affect neuronal survival, implying a shared mechanism of action. These data are consistent with a model in which the neuroprotective activity of Li is mediated, at least in part, through inhibition of GSK-3 $\beta$.

Finally, neurons were treated with myo-inositol in the absence or presence of Li to maintain cytosolic Ino levels. Ino failed to affect Li neuroprotection (Fig. 2D). These data support the notion that IMPases are not the targets of Li neuroprotective responses. Importantly, all of these results using pharmacological modifiers of Li-targeted signaling pathways were repeated and confirmed by substituting HIV-1 gp120 for infected MDM culture fluids and by substituting rat for human neurons as indicator cells (data not shown). Together, these findings demonstrate potential mechanisms for Li-mediated neuroprotection against HIV-1 and macrophage neurotoxins. 


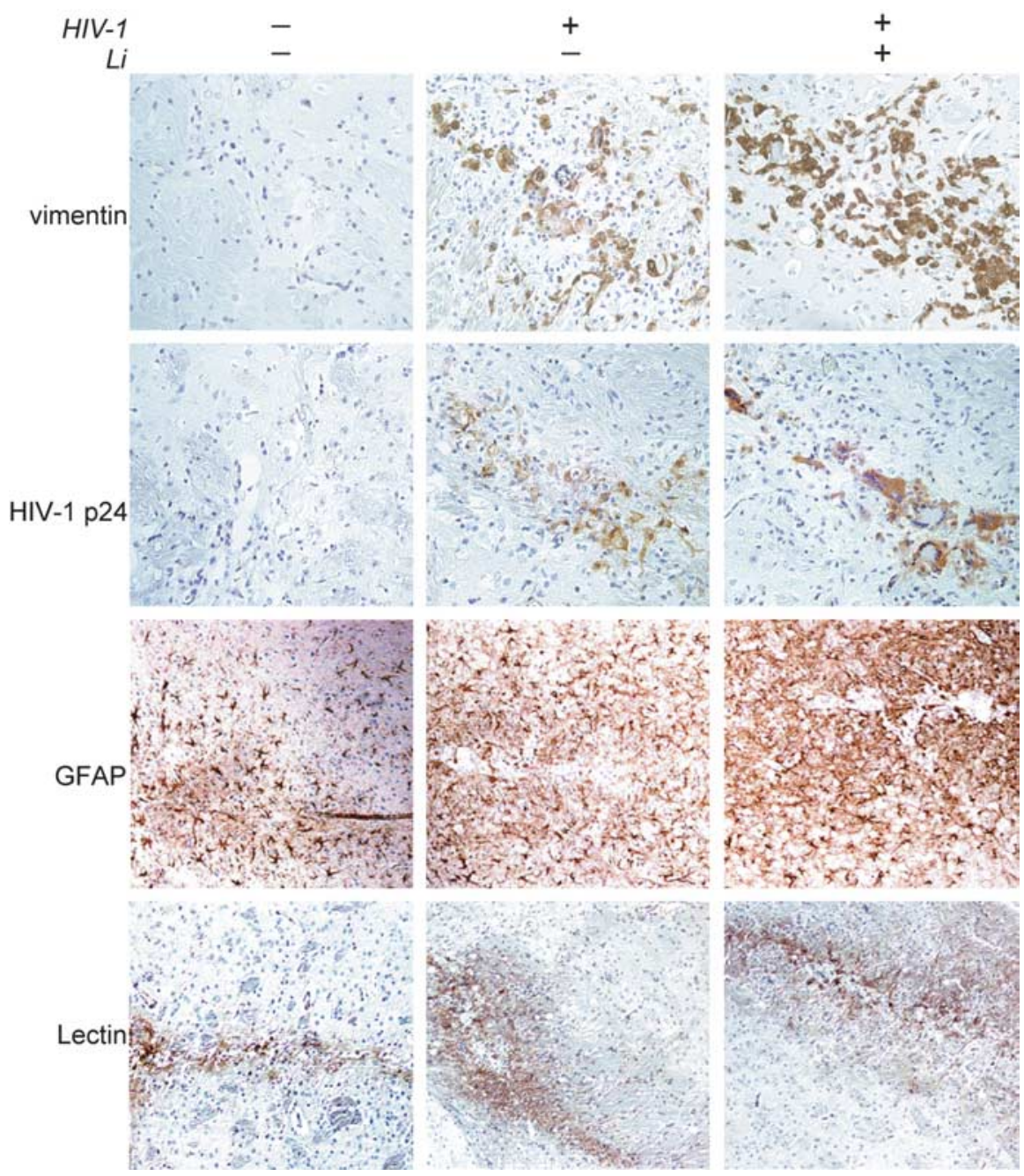

Figure 3. Neuropathological analysis of Li-treated HIVE mice. Serial $5 \mu \mathrm{m}$ brain sections, cut through the needle track, were immunostained for vimentin, HIV-1 p24, GFAP, and lectin. In all cases, the chromagen used to reveal the immunostained cells is brown. Thirty fields in 15 sections were collected from the injection site through the BG and cerebral cortex and subjected to quantitative morphometric analysis. No differences were detected in numbers of human cells (vimentin staining), HIV-1 p24 antigen, astrocyte reactivity (GFAP staining), or microglial activation (lectin staining) in the HIVE mice versus the HIVE mice that were exposed to Li (as shown by the representative microscope fields; immunostaining data not shown). Original magnification, $200 \times$.

\section{Effects of Li on HIV-1 replication and neuroinflammation in murine HIVE}

We next determined whether Li provides neuroprotection in a rodent model of HIVE. In our initial experiments, we analyzed the effects of Li on levels of viral infection and on neuroinflammation. Human HIV-1 ${ }_{\mathrm{ADA}}$-infected MDMs were stereotactically injected into the basal ganglia (BG) of SCID mice. Histopathological changes observed in murine brain tissue paralleled those observed for human HIVE and included HIV-1 infection in perivascular and parenchymal human MDMs, formation of multinucleated giant cells, astrocytosis, and neuronal dropout (Persidsky et al., 1996). Numbers of human uninfected and HIV1-infected MDMs were determined by immunostaining with vimentin and HIV-1 p24 antibodies in serial $5 \mu \mathrm{m}$ brain slices that encompassed the injection site (total cells per section). Numbers of virus-infected and total cell numbers were assessed by examination of 30 fields obtained from 15 separate histological sections. Three sections per mouse and five mice per group (Fig. 3) were examined. At day 7 after injection, the total mean number of MDM was $157.79 \pm 19.79 /$ section and $141 \pm 24.94 /$ section in
HIVE (vehicle) mice and Li-treated HIVE mice, respectively. Of these cells, 26 and $34 \%$ were HIV-1 p 24 positive in untreated and Li-treated HIVE brains, respectively. Li treatment, thus, had no statistically significant effect on $\mathrm{HIV}-1$ replication or MDM engraftment in the HIVE mice. Similarly, astrocyte and microglial reactivity were equivalent in the $\mathrm{Li}$ - and vehicletreated mice. This was revealed by immunostaining of serial brain sections for GFAP (for astrocytes) and G. simplicifolia lectin-isolectin $\mathrm{B}_{4}$ (lectin; for activated microglia) (Fig. 3). Microglial activation (as reflected by the presence of large ramified lectin-positive cells) was detected in and around human MDMs in HIVE mice. The GFAP index (percentage of the microscope field that was positive for GFAP immunoreactivity) was $10.03 \pm 1.67$ and $6.23 \pm 1.13$ in HIVE and sham-operated mice, respectively. The GFAP index of Litreated HIVE mice was $9.33 \pm 1.28$. No differences were observed between $\mathrm{Li}$ - and vehicle-treated HIVE mice in the GFAP index and in microglial reactions. All together, the data demonstrated that Li had no effect on HIV-1 infection, MDM engraftment, or astrocyte and microglial responses.

\section{Neuroprotective activities of $\mathrm{Li}$ in HIVE mice}

The next series of experiments examined possible neuroprotective activities of $\mathrm{Li}$ in the HIVE mice. To assess changes in neuritic processes in the encephalitic mice, double immunostaining with antibodies to MAP-2 and vimentin was used to determine the spatial relationship between neurites and human MDM (Fig. 4). In HIVE animals, MAP-2 (green)-positive neuronal loss extended beyond the areas of MDM (red) in the BG. Li-treated HIVE mice showed significantly higher MAP- $2^{+}$immunoreactivity around sites of HIV-1infected MDMs (Fig. 4). Analysis of immunofluorescent-stained sections showed that Li enhanced neuronal survival and process formation in affected brain tissues with pathological evidence of HIVE.

To examine and quantitate the extent of cell, nuclei, dendrite, and process loss after injection of HIV-1-infected MDM, quantitative immunostaining was performed using antibodies to MAP-2 and SYP (Fig. 5). Minimal neuronal degeneration was observed in sham-operated animals. Significant neuronal loss was detected throughout the BG and cerebral cortex of the HIVE mice when compared with sham-operated animals. This was mostly reversed by Li treatment. Quantitative analysis of digitized microscope images revealed a reduced neuronal index (ratio of MAP-2/NeuN) in HIVE compared with sham-operated mice (Fig. $5 B)(p>0.002$ and $p<0.003$ in BG and cortex, respectively). Li-treated HIVE mice showed MAP-2 staining intensities comparable with sham animals $(p<0.02$ and $p<0.05$ in the BG and cortex, respectively). In sham-operated mice, SYP strongly 
correlated with MAP- $2^{+}$dendrites. SYP expression was also significantly decreased in HIVE mice relative to sham-operated animals $(p<0.03)$. In contrast, Li-treated HIVE mice showed SYP levels that were statistically indistinguishable from sham controls $(p=0.2)$. Overall, HIVE mice showed neuronal nuclei, dendrite, and synaptic cleft loss that was reversed by Li.

\section{Li effects on neural progenitor cells in HIVE mice}

We next evaluated the effects of Li on neural progenitor cells in the DG of HIVE mice. The approach first evaluated expression of MAP-2 to assess alterations in hippocampal neuronal morphology in HIVE mice and its effects by Li (Fig. $6 A$ ). Reductions in MAP-2 staining were observed in the CA1 and DG in HIVE mice compared with sham-operated controls (Fig. $6 B$ ). In contrast, Li-treated HIVE mice showed increased hippocampal MAP-2 expression similar to that of sham controls. Moreover, the length of MAP- $2^{+}$dendrites was reduced in the CA1 $(p<0.003)$ and DG $(p<0.03)$ regions of HIVE mice compared with sham-operated controls. Similarly, in Li-treated HIVE mice, a significant increase in the length of MAP- $2^{+}$ dendrites in the CA1 $(p<0.005)$ and DG $(p<0.03)$ regions was seen compared with HIVE animals. We next evaluated expression of PSA-NCAM as a marker of hippocampal neurogenesis. This is a cell surface marker that is associated with newly generated neurons within the inner border of the granule cell layer (GCL). Small, round, PSA-NCAM ${ }^{+}$cells with dark nuclei were found bordering the polymorph layer (hilus) and the DG GCL but not the CA1 region. Cells with apical dendrites or with marked dendritic processes extending from the GCL to molecular layer were observed. HIVE mice showed reduced numbers of PSA-NCAM ${ }^{+}$cells (number of PSA-NCAM ${ }^{+}$cell/millimeter of length of the hippocampus) in the DG when compared with sham-operated mice (Fig. 6C) $(p<0.0002)$. Li significantly increased PSA-NCAM ${ }^{+}$ cell numbers compared with the untreated mice $(p<0.002)$. Quantitative analysis of dendritic length on PSA-NCAM ${ }^{+}$neurons further revealed the protective effects of Li treatment (Fig. $6 D, E)$. The average numbers of dendrites expressed on the cells (numbers of PSA-NCAM ${ }^{+}$dendrites/millimeter of length of the hippocampus) were also reduced in HIVE mice relative to sham controls $(p<0.001)$, as was the average length of dendrites $(p<$ $0.01)$. Li increased both PSA-NCAM ${ }^{+}$dendrite numbers $(p<$ $0.01)$ and length $(p<0.03)$ in the HIVE mice.

\section{Physiology of Li-induced neuroprotection}

In our previous studies, we demonstrated that synaptic dysfunction peaked in HIVE animals $7 \mathrm{~d}$ after HIV-1-infected MDM injection and that these functional deficits persisted for $>15 \mathrm{~d}$ (Zink et al., 2002; Anderson et al., 2003). To assess the physiological basis of Li-induced neuroprotection, we analyzed LTP activity using hippocampal slides that were prepared from shamoperated (controls) and from HIV mice with and without Li treatment. As shown in Figure 7, field EPSP traces from the CA1 region were recorded at $60 \mathrm{~min}$ after HFS. Average LTP magnitudes recorded in control animals were $263.2 \pm 32.5 \%$ of basal levels $(n=7)$ and from animals injected with HIV-1-infected MDM; LTP magnitudes were $106.6 \pm 29.2 \%$ of basal levels $(n=$ $7 ; p<0.01$ ). Notably, administration of Li in mice injected with HIV-1-infected MDM led to LTP enhancement. The average LTP magnitude was $192.2 \pm 29.4 \%$ relative to basal activity $(n=5$; $p<0.05$ ). These results demonstrate that Li protects neuronal synaptic function in HIVE mice.

\section{Li neuroprotection and GSK-3 $\beta$ activity in HIV mice}

Li-mediated neuroprotection in HIVE mice was analyzed in lysates of brain tissue protein by Western blot assays (Fig. $8 A$ ). In Figure $8 B$, a modest decrease in total $\beta$-catenin and GSK- $3 \beta$, with a concomitant rise in $\mathrm{p}$ - $\beta$-catenin, is illustrated in HIVE mice $(p<0.01)$ when compared with sham-operated animals. These changes were mostly reversed by Li (Fig. $8 B$ ). To evaluate the potential role of phosphorylated Tau in HIV-1-mediated neuronal injury, immunoblot analysis of tissue extracts was performed using antibodies specific for phosphorylated Tau $\left(\mathrm{Ser}^{202}\right.$, $\mathrm{Thr}^{181}$ ) or total Tau (Tau5 antibody) (Fig. 8C). Quantitation of total Tau and phosphorylated Tau Ser ${ }^{202}$ was performed in HIVE mice. All groups showed similar Tau5 immunoreactivity (total Tau). In contrast, the levels of Tau phosphorylation increased in HIVE animals compared with sham-operated controls $(p<$ 0.01). Li-treated HIVE mice showed a significant reduction in phospho-Tau Ser ${ }^{202}$ compared with vehicle-treated HIVE ani- 
A

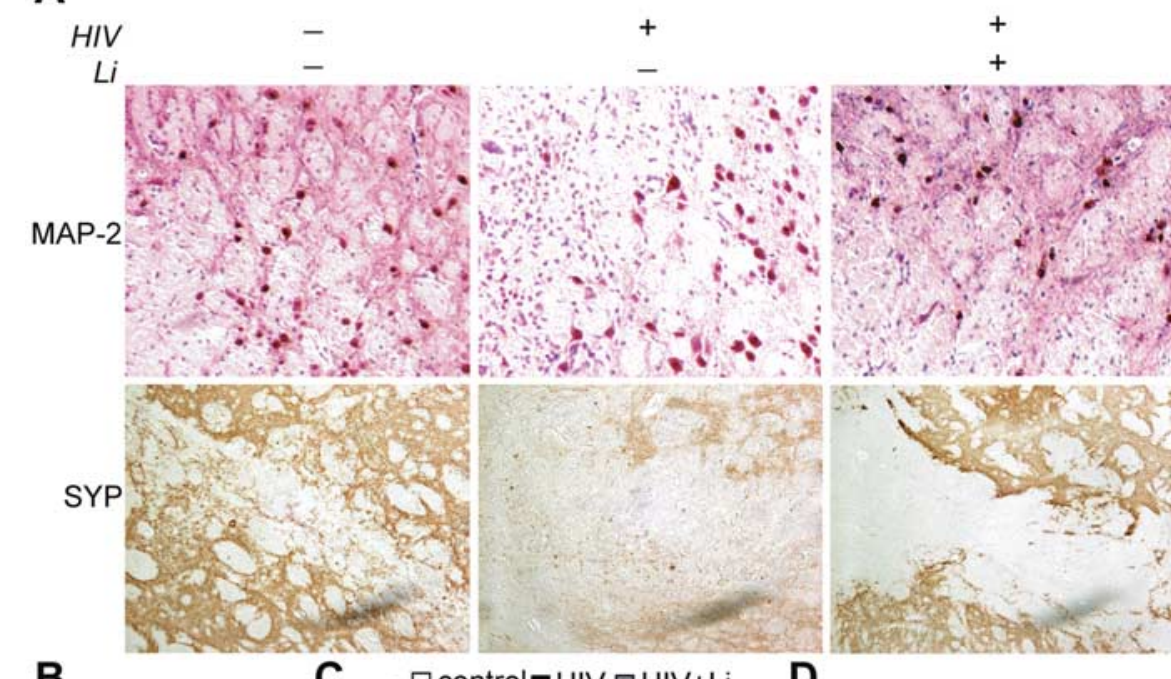

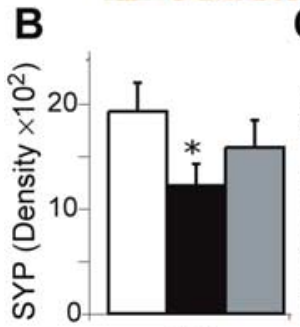

BG C $\square$ control $\mathbf{m I V} \square \mathrm{HIV}+\mathrm{Li}$
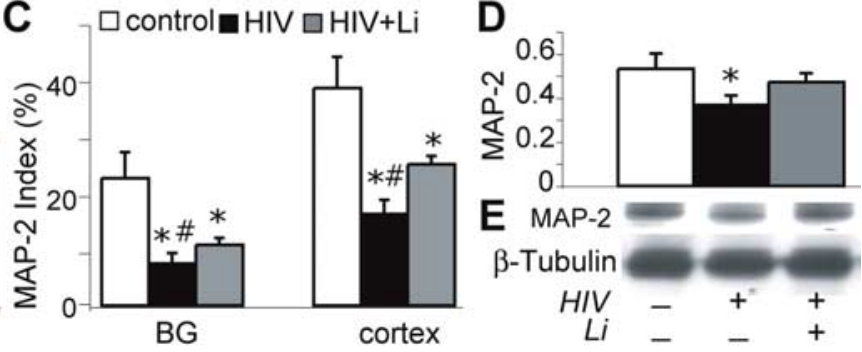

Figure 5. Li protects neuronal dendrites and synaptic clefts. $\boldsymbol{A}$, Immunostaining was performed on serial $5 \mu \mathrm{m}$ formalin-fixed paraffin-embedded brain tissue sections with antibodies to MAP-2 (a marker for dendrites; purple stain, top panels) and SYP (a marker for synaptic clefts; brown stain, bottom panels). $\boldsymbol{B}$, Quantitation of SYP immunostaining also revealed a significant loss of SYP $^{+}$synapses in the BG HIVE mice (filled bars), relative to untreated control mice (open bars) $(p<0.03)$. This loss of SYP ${ }^{+}$ staining density in the HIVE mice was restored by treatment with Li (gray bars). C, Quantitative analysis of the immunostained sections revealed that there was a significant loss of MAP-2 ${ }^{+}$dendrites in the BG and cortex of HIVE mice (filled bars) relative to untreated control mice (open bars) ( $p<0.002$ for BG; $p<0.003$ for cortex, respectively). Li treatment partially restored MAP-2 levels in both sites in the HIVE mice (gray bars; $p<0.02$ and $p<0.05$ in the BG and in the cortex). $\boldsymbol{D}, \boldsymbol{E}$, To confirm histological results for MAP-2 levels, brain tissue protein was analyzed by quantitative Western blot assays. Data were normalized by $\beta$-tubulin. HIVE mice showed lower levels of MAP-2 compared with control $(p<0.05)$. Li treated to HIVE animals showed an increase in MAP-2 levels. Original magnification, $200 \times$. The asterisk denotes a statistically significant difference when compared with sham mice; the number sign denotes a statistically significant difference compared with Li-treated HIVE mice.

mals $(p<0.03)$. These data are consistent with a decrease in GSK- $3 \beta$ activity after Li treatment.

\section{Mechanisms of Li neuroprotection}

To further examine the potential mechanisms by which Li treatment may protect neurons against candidate HIV-1 neurotoxins, we performed in vitro experiments using human fetal neurons exposed to $\mathrm{HIV}-1^{+}$fluids. The effects of $\mathrm{Li}$ on the expression levels and phosphorylation status of GSK- $3 \beta$ and $\beta$-catenin were analyzed by Western blot assays using isoform-specific antibodies (Fig. 9A). Quantitative analysis (Fig. 9B-E) of these experiments, as expected, revealed that neuron exposure to HIV $-1^{+}$ MDM culture fluids resulted in an increase in $\beta$-catenin phosphorylation $(p<0.01)$ (Fig. 9E) and a decrease in the levels of Ser $^{9}$-phosphorylated GSK-3 $\beta(p<0.01)$ (Fig. 9E). Changes in $\beta$-catenin and GSK-3 $\beta$ phosphorylation were reversed by $\mathrm{Li}$ $(p<0.01)$ for both $\mathrm{p}-\beta$-catenin and Ser ${ }^{9}$-p-GSK-3 $\beta$ (Fig. 9C,E). This was observed in the absence of changes in the overall expression levels of either protein. The highly specific GSK-3 $\beta$ inhibitor, Ind, had essentially identical effects on $\beta$-catenin phosphorylation and levels of Ser ${ }^{9}$-phosphorylated GSK-3 $\beta$.

Because GSK-3 $\beta$ is a downstream target for PI3-K, we also investigated whether the Li neuroprotective effects involved activation of the PI-3kinase/AKT pathway, using the PI3kinase-specific inhibitor LY. Treatment with LY reversed the effects of $\mathrm{Li}$ on both $\beta$-catenin phosphorylation and levels of Ser ${ }^{9}$-phosphorylated GSK-3 $\beta$. Neurons exposed to $\mathrm{HIV}-1^{+}$fluids treated with $\mathrm{Li}$ induced GSK-3 $\beta$ phosphorylation. Together, our results suggest that the neuroprotective effects of $\mathrm{Li}$ involve activation of the PI-3-kinase/AKT pathway, inhibition of GSK-3 $\beta$, and accumulation of $\beta$-catenin. These data further support the involvement of the GSK-3 $\beta$ and PI-3-kinase/Akt pathways in Li neuroprotective activities.

\section{Discussion}

We demonstrate that Li protects neurons against HIV-1-infected macrophage neurotoxins in both a laboratory and an animal model system of HIVE and HAD. In recent years, $\mathrm{Li}$ was shown to possess neuroprotective activities in addition to its known abilities to positively affect the treatment of bipolar disorders. Moreover, it is now well established that Li elicits neuroprotection, in part, through its ability to inhibit GSK-3 $\beta$ (Hong et al., 1997; Everall et al., 2002; Facci et al., 2003; Hongisto et al., 2003; Kirshenboim et al., 2004).

One mechanism whereby Li can inhibit GSK- $3 \beta$ is through increasing the phosphorylation of a key inhibitory site of GSK-3 $\beta$, Ser ${ }^{9}$ (Zhang et al., 2003); this process is reduced by inhibition of protein kinase C (PKC) (Lenox et al., 1996; Kirshenboim et al., 2004). Because PI3-kinase is a potential upstream regulator of $\mathrm{PKC}$, its inhibition by LY294002 might be expected to affect Li-induced phosphorylation of the $\operatorname{Ser}^{9}$ residue of GSK-3 $\beta$ in neurons. Our data support this idea and show that Li-mediated neuroprotective activities involve activation of PI-3kinase/AKT but not depletion of inositol. Thus, Li may interfere with the proapoptotic effects of candidate HIV-1 neurotoxins by affecting phosphatidylinositol 3 kinase-dependent activation of PKC. The inhibition of Li-mediated neuronal protection by LY294002 strongly supports this notion. Li may target not only the PI3K/Akt survival pathway (Stambolic et al., 1996; Mora et al., 2001; De Sarno et al., 2002, Sinha et al., 2005) but also GSK$3 \beta$-mediated signaling to accomplish its protective effects in neurons exposed to candidate HIV-1 neurotoxins.

A previous study demonstrated that Li treatment can increase BDNF and the phosphorylation of TrkB at Tyr490, suggesting that $\mathrm{Li}$ affects BDNF production leading to activation of the TrkB receptor (Hashimoto et al., 2002). Our in vitro studies showed that K252a, an inhibitor of Trk receptor tyrosine kinase activity, did not block the anti-apoptosis effects of Li. Thus, the neuroprotective effects of Li are mediated independently of TrkB signaling pathways.

This study is multifaceted and complex in both design and 
analysis. Laboratory studies and those in a rodent model of human HAD show changes in structure, function, and development of neurons. We demonstrated previously that alterations in neuronal physiology can occur as a consequence of the introduction of HIV-1-infected macrophages into the CNS (Xiong et al., 1999; Anderson et al., 2003). Impairment in hippocampal function was also shown as reflected by deficits in LTP, which may underlie the cognitive dysfunction seen in a patient with autoimmunodeficiency syndrome. HIV-1-mediated neuronal damage may contribute to these changes in neuronal physiology by reducing the complexity of the dendritic architecture, thereby causing an intrinsically lower capacity for LTP induction in the HIVE mice. This is supported by morphological changes in MAP-2 staining and increases in Li-induced dendritic lengths in HIVE animals (changes that we have shown previously to occur not only in brain regions proximal to the site of injection of HIV-1infected MDM but also at distant anatomic sites, including the ipsilateral cortex and hippocampus).

HAD is a metabolic encephalopathy fueled by HIV-1-infected and immuneactivated mononuclear phagocytes (MPs; perivascular and parenchymal macrophages and microglia) that secrete a plethora of viral and cellular neurotoxins. At the clinical level, it is characterized by significant cognitive, motor, and behavioral abnormalities (Ivanisevic, 1987; Lipton and Gendelman, 1995; Gendelman et al., 1997) and is pathologically linked to a gi-

ant cell encephalitis referred to commonly as HIV-1 encephalitis (Gelbard et al., 1994; Navia, 1997; Zink et al., 1999). Virus infection and immune activation of MPs, astrogliosis, myelin pallor, and neuronal dropout are prominent neuropathological features of disease (Navia et al., 1986). MPs may also affect the pruning of neuronal dendrites and changes in synaptic processes linked to disease (Masliah et al., 1996). The mechanisms underlying neuronal injury for HAD are mirrored in our laboratory and in HIVE SCID mouse models of human disease. These two model systems demonstrate the importance of HIV-infected or activated MPs in inducing neuronal dysfunction through the secretion of cellular and viral toxins including proinflammatory cytokines, glutamate, and a variety of excitotoxins (Genis et al., 1992; Nottet et al., 1995; Persidsky et al., 1996, 1997; Anderson et al., 2003). Previous studies performed in our laboratories also demonstrated that sodium valproate induces neuroprotective effects by downregulation of Tau phosphorylation and GSK-3 $\beta$ in HIVE mice (Dou et al., 2003). Although both valproic acid and Li affect GSK-3 $\beta$ and Tau phosphorylation, the mechanisms of neuronal protection were found, in part, to be distinct.

All together, we demonstrate that $\mathrm{Li}$ induces neuroprotective activities in laboratory and animal models of HIVE. Although a range of cell-signaling pathways affect neuronal function in HAD
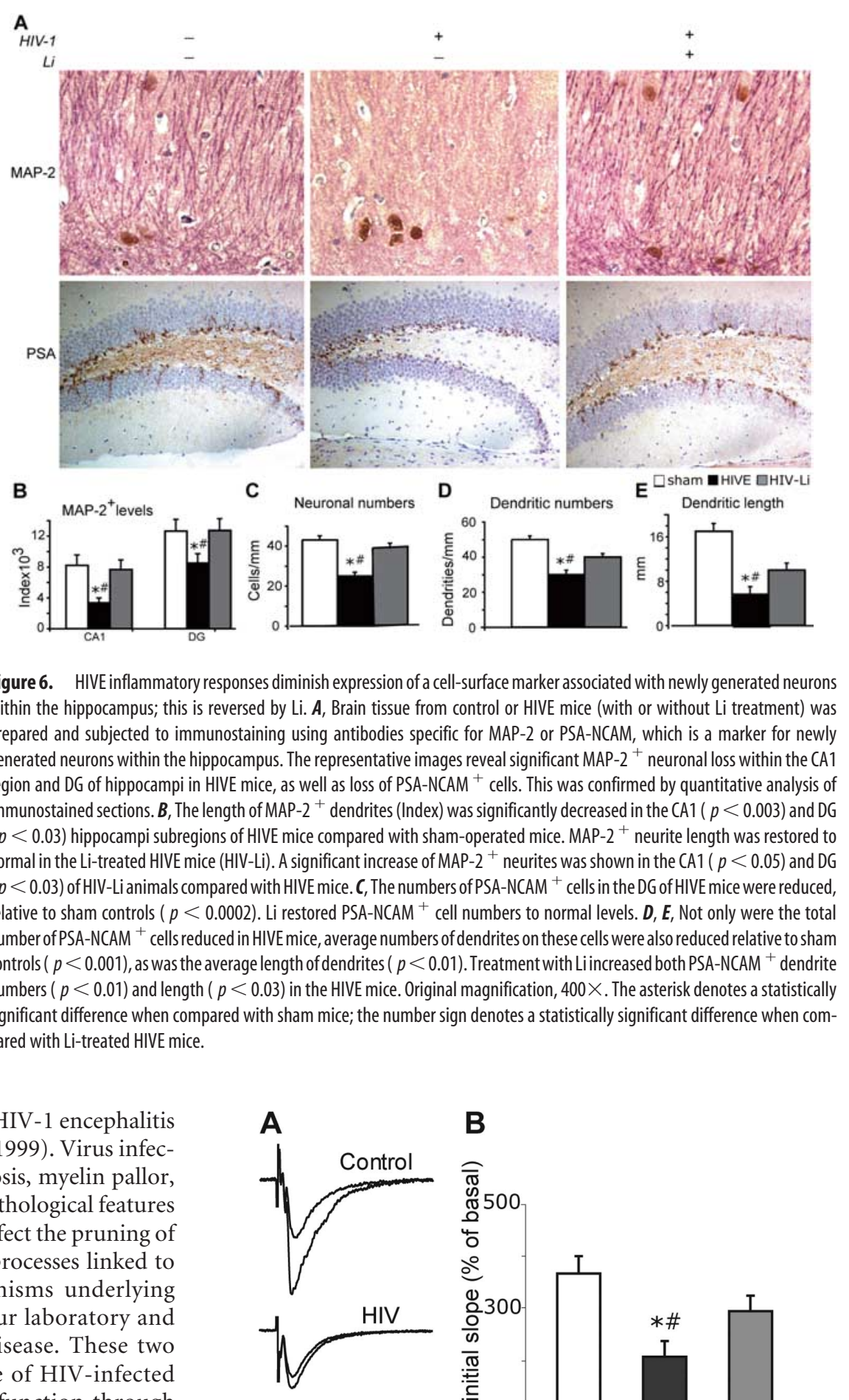

Figure 6. HIVE inflammatory responses diminish expression of a cell-surface marker associated with newly generated neurons within the hippocampus; this is reversed by Li. $\boldsymbol{A}$, Brain tissue from control or HIVE mice (with or without Li treatment) was prepared and subjected to immunostaining using antibodies specific for MAP-2 or PSA-NCAM, which is a marker for newly ( $p<0.03)$ of HIV-Li animals compared with HIVE mice. $C$, The numbers of PSA-NCAM ${ }^{+}$cells in the DG of HIVE mice were reduced controls $(p<0.0002)$. Li restored PSA-NCAM cell numbers to normal levels. $\boldsymbol{D}, \boldsymbol{E}$, Not only were the tota controls $(p<0.001)$, as was the average length of dendrites $(p<0.01)$. Treatment with Li increased both PSA-NCAM ${ }^{+}$dendrite pared with Li-treated HIVE mice.

B
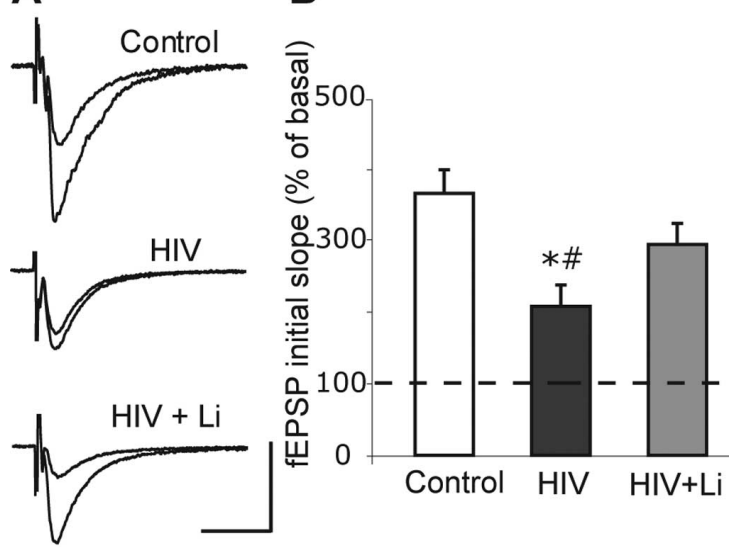

Figure 7. Diminished LTP in both the ipsilateral and contralateral hippocampi after injection of HIV-1-infected MDM into the left BG. $\boldsymbol{A}$ illustrates the magnitude of LTP recorded from hippocampal brain slices from sham-operated animals (control), HIVE SCID mice (HIV), and HIV mice treated with Li (HIV+Li). $\boldsymbol{B}$ shows LTP measured 70 min after HFS. No significant difference ( $p>0.05$ ) was observed between the two hemispheres. Diminished LTP levels were recorded in HIVE mice when compared with sham mice ( $p<0.05)$; Li treatment significantly improved this functional measure in these animals $(p<0.05)$. The asterisk denotes a statistically significant difference when compared with sham mice; the number sign denotes a statistically significant difference when compared with Li-treated HIVE mice. 

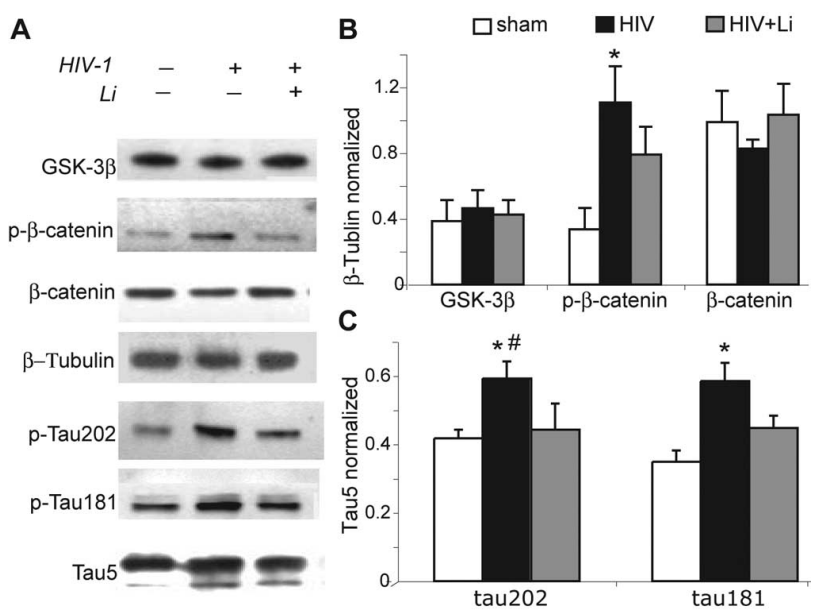

Figure 8. Pathways for Li-mediated neuroprotection in HIVE mice. $\boldsymbol{A}$, Western blot assays were performed on tissue extracts using antibodies specific for GSK-3 $\beta$, phosphorylated $\beta$-catenin, $\beta$-catenin, Tau (all isoforms; Tau5 antibody), and two phosphorylated isoforms of $\mathrm{Tau}\left(\mathrm{Ser}^{202}\right.$ and Thr $\left.{ }^{181}\right)$. B, C, Data were quantitated densitometrically. As expected, expression levels of GSK-3 $\beta$ were unaltered in all groups of mice. Total levels of $\beta$-catenin were slightly reduced in the HIVE mice relative to sham controls, whereas levels of phosphorylated $\beta$-catenin were significantly upregulated in the HIVE mice $(p<0.05)$. This is consistent with a rise in the enzymatic activity of GSK-3 $\beta$ in the HIVE animals. Li treatment essentially reversed these effects on $\beta$-catenin. C, Quantitative analysis of the Tau phosphorylation at residues 202 and 181 was performed by measuring immunoreactivity with phospho-specific antisera directed against the $\mathrm{Tau}^{202}$ and $\mathrm{Tau}^{181}$ residues and then normalizing the resulting densitometric data in terms of total Tau immunoreactivity (determined using the Tau 5 antibody, which recognizes all forms the protein). This analysis revealed increases in both $\operatorname{Ser}^{202}(p<0.05)$ and $\mathrm{Thr}^{181}$ $(p<0.01)$ phosphorylated isoforms of Tau in HIVE mice (HIV), compared with control animals (sham). These changes were reversed by Li treatment of HIVE mice. The asterisk denotes a statistically significant difference when compared with sham mice; the number sign denotes a statistically significant difference when compared with Li-treated HIVE mice.
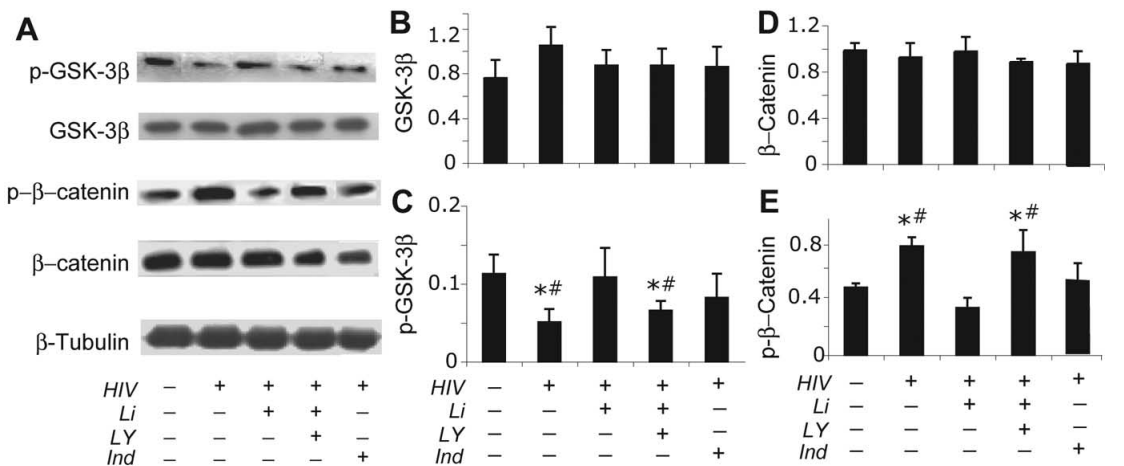

Figure 9. Engagement of GSK-3 $\beta$ and $\beta$-catenin phosphorylation in Li-mediated neuroprotection. $\boldsymbol{A}$, Culture fluids from HIV-1-infected MDM [25\% (v/v)] were added to human fetal neurons in the presence or absence of $10 \mathrm{~mm}$ Li and the indicated compounds ( $L Y$ and $I n d)$ for $2 \mathrm{~h}$. Neuronal cell lysates were then prepared and subjected to Western blot assays using antibodies specific for total GSK-3 $\beta$, phospho-serine9 GSK-3 $\beta, \beta$-catenin, and phospho-serine ${ }^{33,37}$ - $\beta$-catenin. $\boldsymbol{B}$, $\boldsymbol{C}$, Li reduced Ser $^{9}$ phos- $^{-}$ phorylation of GSK-3 $\beta$. Quantitative analysis of immunoblots performed from neuronal lysates demonstrated that total GSK-3 $\beta$ levels were not statistically different in untreated cells versus cells exposed to HIV- ${ }^{+}$fluids, regardless of the presence of Li. $B$, In contrast, phosphorylation of GSK-3 $\beta$ Ser $^{9}$ was decreased after $5 \mathrm{~d}$ of neuronal exposure to HIV- ${ }^{+}$culture fluids when compared with replicate neurons treated with culture fluids from uninfected MDMs (control; $p<0.01$ ) and Li-treated cells exposed to HIV-infected materials $(p<0.03)$. C, When LY, in combination with Li, was exposed to neurons treated with HIV-1 ${ }^{+}$fluids, GSK-3 $\beta$ Ser $^{9}$ phosphorylation was reduced compared with replicate neuronal cultures given $\mathrm{Li}(p<0.05)$ or with negative controls $(p<0.02)$. GSK-3 $\beta$ phosphorylation was also increased by Ind $(p<0.05)$. $\boldsymbol{D}, \boldsymbol{E}$, Li reduced $\beta$-catenin phosphorylation. Total $\beta$-catenin levels $(\boldsymbol{D})$ were unaltered by exposure to HIV-1 ${ }^{+}$fluids or treatment with Li. HIV- ${ }^{+}$culture fluids did, however, induce significant levels of phospho-serine ${ }^{33,37}$ - $\beta$-catenin, relative to control culture fluids $(p<0.03$ and $p<0.02$ ). These levels were reduced by $\mathrm{Li}(p<0.05$ ) and negated when LY was added to cells with $\mathrm{Li}$ ( $p<0.05$ and $p<0.05$ ), compared with cells treated with control fluids or HIV-1 ${ }^{+}$fluids in the presence of Li. Finally, Ind diminished the phosphorylation of $\beta$-catenin at $\mathrm{Ser}^{33,37}$ regardless of the addition of Li. These results are representative of three individual experiments done in quadruplicate determinations (the asterisk denotes a statistically significant difference when compared in a pairwise manner to untreated control cells that did not receive HIV-1 ${ }^{+}$fluids; the number sign denotes a statistically significant difference compared with cultures that were exposed to HIV-1 ${ }^{+}$fluids in the presence of Li).
(Fiscus, 2002; Garden et al., 2002; Bodner et al., 2004), the GS- $3 \beta$ pathway, in particular, is a major contributor to neuromechanisms through which GSK-3 $\beta$ activation may promote . brains of individuls with advanced HIV 1 infection (Stanley al., 1994). Thus, this signaling pathway is an attractive therapeutic target for treatment of HAD. This idea is further supported by reports demonstrating that Tau is elevated in the CSF of HIV-1 al., 1998) and that Tau levels correlate with brain atrophy seen by magnetic resonance imaging (Green et al., 2000). Although the pathways through which HIV- 1 affects GSK- $3 \beta$ activation and subsequent Tau phosphorylation remain unclear, we have now puccessfully that Li prolongs neuronal survival, man HIVE.

Neuronal and synaptic impairments are attenuated by Li. LTP promotes stabilization and growth of synaptic connections, primarily through the induction of new protein synthesis. A primary clinical manifestation of HAD is memory and behavioral impairments associated with virus-mediated neuronal dysfunction and we (Wilkie et al., 1992; Heaton et al., 2004). In support of this, behavioral and cognitive impairments in HIVE mice (Xiong et al., 1999; Anderson et al., 2003, 2004; Xiong et al., 2003). Our electrophysiological findings suggest that Li can restore hippocampal synaptic transmission during HIVE. This may be related to protection of dendritic and synaptic architecture, because Li treatment was associated with preservation of MAP-2 ${ }^{+}$ dendrites and SYP expression. In this context, it is noteworthy that $\mathrm{Li}$ has been shown previously to affect neuronal SYP expression in other experimental paradigms through effects on both inositol metabolism (O'Donnell et al., 2000; Williams et al., 2002) and PI3-K/Akt signaling (Chalecka-Franaszek and Chuang, 1999; Mora et al., 1999). Our results suggest that only the latter pathway may be relevant to the protective effects of $\mathrm{Li}$ on neurons exposed to HIV-1 and macrophage neurotoxins.

In conclusion, our results show that Li exerts powerful neuroprotective effects that include neuronal survival, architecture, and function in a murine model of HIVE. At the same time, Li had no appreciable effects on HIV-1 replication or on microglial and astrocyte activation. Thus, the protective effects of $\mathrm{Li}$ appear to be chiefly attributable to its effects on neurons. The results suggest that Li may be used as adjunctive therapy for HAD. Combinations of Li, together with potent anti-retroviral therapies and anti-inflammatory therapies, may be particularly effective in the clinic. 


\section{References}

Anderson ER, Boyle J, Zink WE, Persidsky Y, Gendelman HE, Xiong H (2003) Hippocampal synaptic dysfunction in a murine model of human immunodeficiency virus type 1 encephalitis. Neuroscience 118:359-369.

Anderson ER, Gendelman HE, Xiong H (2004) Memantine protects hippocampal neuronal function in murine human immunodeficiency virus type 1 encephalitis. J Neurosci 24:7194-7198.

Berry GT, Buccafusca R, Greer JJ, Eccleston E (2004) Phosphoinositide deficiency due to inositol depletion is not a mechanism of lithium action in brain. Mol Genet Metab 82:87-92.

Bhat RV, Budd Haeberlein SL, Avila J (2004) Glycogen synthase kinase 3: a drug target for CNS therapies. J Neurochem 89:1313-1317.

Bodner A, Toth PT, Miller RJ (2004) Activation of c-Jun N-terminal kinase mediates gp120IIIB- and nucleoside analogue-induced sensory neuron toxicity. Exp Neurol 188:246-253.

Brunello N (2004) Mood stabilizers: protecting the mood, protecting the brain. J Affect Disord 79 [Suppl 1]:S15-S20.

Chalecka-Franaszek E, Chuang DM (1999) Lithium activates the serine/ threonine kinase Akt-1 and suppresses glutamate-induced inhibition of Akt- 1 activity in neurons. Proc Natl Acad Sci USA 96:8745-8750.

De Sarno P, Li X, Jope RS (2002) Regulation of Akt and glycogen synthase kinase- 3 beta phosphorylation by sodium valproate and lithium. Neuropharmacology 43:1158-1164.

Dou H, Birusingh K, Faraci J, Gorantla S, Poluektova LY, Maggirwar SB, Dewhurst S, Gelbard HA, Gendelman HE (2003) Neuroprotective activities of sodium valproate in a murine model of human immunodeficiency virus- 1 encephalitis. J Neurosci 23:9162-9170.

Ellis RJ, Seubert P, Motter R, Galasko D, Deutsch R, Heaton RK, Heyes MP, McCutchan JA, Atkinson JH, Grant I (1998) Cerebrospinal fluid tau protein is not elevated in HIV-associated neurologic disease in humans. HIV Neurobehavioral Research Center Group (HNRC). Neurosci Lett 254:1-4.

Everall IP, Bell C, Mallory M, Langford D, Adame A, Rockestein E, Masliah E (2002) Lithium ameliorates HIV-gp120-mediated neurotoxicity. Mol Cell Neurosci 21:493-501.

Facci L, Stevens DA, Skaper SD (2003) Glycogen synthase kinase-3 inhibitors protect central neurons against excitotoxicity. NeuroReport 14:1467-1470.

Fiscus RR (2002) Involvement of cyclic GMP and protein kinase G in the regulation of apoptosis and survival in neural cells. NeuroSignals 11:175-190.

Garden GA, Budd SL, Tsai E, Hanson L, Kaul M, D’Emilia DM, Friedlander RM, Yuan J, Masliah E, Lipton SA (2002) Caspase cascades in human immunodeficiency virus-associated neurodegeneration. J Neurosci 22:4015-4024.

Gelbard HA, Nottet HS, Swindells S, Jett M, Dzenko KA, Genis P, White R, Wang L, Choi Y-B, Zhang D, Lipton SA, Tourtellotte WW, Epstein LG, Gendelman HE (1994) Platelet-activating factor: a candidate human immunodeficiency virus type 1-induced neurotoxin. J Virol 68:4628-4635.

Gendelman HE, Orenstein JM, Martin MA, Ferrua C, Mitra R, Phipps T, Wahl LA, Lane HC, Fauci AS, Burke DS, Skillman D, Meltzer MS (1988) Efficient isolation and propagation of human immunodeficiency virus on recombinant colony-stimulating factor 1-treated monocytes. J Exp Med 167:1428-1441.

Gendelman HE, Persidsky Y, Ghorpade A, Limoges J, Stins M, Fiala M, Morrisett R (1997) The neuropathogenesis of the AIDS dementia complex. AIDS 11 [Suppl A]:S35-S45.

Genis P, Jett M, Bernton EW, Boyle T, Gelbard HA, Dzenko K, Keane RW, Resnick L, Mizrachi Y, Volsky DJ, Epstein LG, Gendelman HE (1992) Cytokines and arachidonic metabolites produced during human immunodeficiency virus (HIV)-infected macrophage-astroglia interactions: implications for the neuropathogenesis of HIV disease. J Exp Med 176:1703-1718.

Green AJ, Giovannoni G, Hall-Craggs MA, Thompson EJ, Miller RF (2000) Cerebrospinal fluid tau concentrations in HIV infected patients with suspected neurological disease. Sex Transm Infect 76:443-446.

Harwood AJ, Agam G (2003) Search for a common mechanism of mood stabilizers. Biochem Pharmacol 66:179-189.

Hashimoto R, Takei N, Shimazu K, Christ L, Lu B, Chuang DM (2002) Lithium induces brain-derived neurotrophic factor and activates TrkB in rodent cortical neurons: an essential step for neuroprotection against glutamate excitotoxicity. Neuropharmacology 43:1173-1179.

Hashimoto R, Fujimaki K, Jeong MR, Christ L, Chuang DM (2003a) Lithium-induced inhibition of Src tyrosine kinase in rat cerebral cortical neurons: a role in neuroprotection against $N$-methyl-D-aspartate receptor-mediated excitotoxicity. FEBS Lett 538:145-148.

Hashimoto R, Fujimaki K, Jeong MR, Senatorov VV, Christ L, Leeds P, Chuang DM, Takeda M (2003b) Neuroprotective actions of lithium. Seishin Shinkeigaku Zasshi 105:81-86.

Heaton RK, Marcotte TD, Mindt MR, Sadek J, Moore DJ, Bentley H, McCutchan JA, Reicks C, Grant I (2004) The impact of HIV-associated neuropsychological impairment on everyday functioning. J Int Neuropsychol Soc 10:317-331.

Hernandez F, Lucas JJ, Cuadros R, Avila J (2003) GSK-3 dependent phosphoepitopes recognized by PHF-1 and AT- 8 antibodies are present in different tau isoforms. Neurobiol Aging 24:1087-1094.

Hokin LE, Dixon JF, Los GV (1996) A novel action of lithium: stimulation of glutamate release and inositol 1,4,5 trisphosphate accumulation via activation of the $N$-methyl D-aspartate receptor in monkey and mouse cerebral cortex slices. Adv Enzyme Regul 36:229-244.

Hong M, Chen DC, Klein PS, Lee VM (1997) Lithium reduces tau phosphorylation by inhibition of glycogen synthase kinase-3. J Biol Chem 272:25326-25332.

Hongisto V, Smeds N, Brecht S, Herdegen T, Courtney MJ, Coffey ET (2003) Lithium blocks the c-Jun stress response and protects neurons via its action on glycogen synthase kinase 3. Mol Cell Biol 23:6027-6036.

Hoshi M, Sato M, Kondo S, Takashima A, Noguchi K, Takahashi M, Ishiguro K, Imahori K (1995) Different localization of tau protein kinase I/glycogen synthase kinase- 3 beta from glycogen synthase kinase- 3 alpha in cerebellum mitochondria. J Biochem (Tokyo) 118:683-685.

Hoshi M, Takashima A, Noguchi K, Murayama M, Sato M, Kondo S, Saitoh Y, Ishiguro K, Hoshino T, Imahori K (1996) Regulation of mitochondrial pyruvate dehydrogenase activity by tau protein kinase I/glycogen synthase kinase 3beta in brain. Proc Natl Acad Sci USA 93:2719-2723.

Ivanisevic V (1987) Neurologic manifestations of the acquired immunodeficiency syndrome. Vojnosanit Pregl 44:440-443.

Jope RS (1999) Anti-bipolar therapy: mechanism of action of lithium. Mol Psychiatry 4:117-128.

Jope RS, Bijur GN (2002) Mood stabilizers, glycogen synthase kinase-3beta and cell survival. Mol Psychiatry 7 [Suppl 1]:S35-S45.

Kim JW, Lee JE, Kim MJ, Cho EG, Cho SG, Choi EJ (2003) Glycogen synthase kinase 3 beta is a natural activator of mitogen-activated protein kinase/extracellular signal-regulated kinase kinase kinase 1 (MEKK1). J Biol Chem 278:13995-14001.

Kirshenboim N, Plotkin B, Shlomo SB, Kaidanovich-Beilin O, EldarFinkelman H (2004) Lithium-mediated phosphorylation of glycogen synthase kinase-3b involves PI3 kinase-dependent activation of protein kinase C-alpha. J Mol Neurosci 24:237-245.

Klein PS, Melton DA (1996) A molecular mechanism for the effect of lithium on development. Proc Natl Acad Sci USA 93:8455-8459.

Lenox RH, McNamara RK, Watterson JM, Watson DG (1996) Myristoylated alanine-rich C kinase substrate (MARCKS): a molecular target for the therapeutic action of mood stabilizers in the brain? J Clin Psychiatry 57 [Suppl 13]:23-33.

Li X, Bijur GN, Jope RS (2002) Glycogen synthase kinase-3beta, mood stabilizers, and neuroprotection. Bipolar Disord 4:137-144.

Lipton SA, Gendelman HE (1995) Seminars in medicine of the Beth Israel Hospital, Boston. Dementia associated with the acquired immunodeficiency syndrome. N Engl J Med 332:934-940.

Maggirwar SB, Tong N, Ramirez S, Gelbard HA, Dewhurst S (1999) HIV-1 Tat-mediated activation of glycogen synthase kinase-3beta contributes to Tat-mediated neurotoxicity. J Neurochem 73:578-586.

Masliah E, Ge N, Mucke L (1996) Pathogenesis of HIV-1 associated neurodegeneration. Crit Rev Neurobiol 10:57-67.

Mora A, Gonzalez-Polo RA, Fuentes JM, Soler G, Centeno F (1999) Different mechanisms of protection against apoptosis by valproate and $\mathrm{Li}+$. Eur J Biochem 266:886-891.

Mora A, Sabio G, Gonzalez-Polo RA, Cuenda A, Alessi DR, Alonso JC, Fuentes JM, Soler G, Centeno F (2001) Lithium inhibits caspase 3 activation and dephosphorylation of PKB and GSK3 induced by $\mathrm{K}^{+}$deprivation in cerebellar granule cells. J Neurochem 78:199-206. 
Navia BA (1997) Clinical and biologic features of the AIDS dementia complex. Neuroimaging Clin N Am 7:581-592.

Navia BA, Jordan BD, Price RW (1986) The AIDS dementia complex. I. Clinical features. Ann Neurol 19:517-524.

Nottet HS, Jett M, Flanagan CR, Zhai QH, Persidsky Y, Rizzino A, Bernton EW, Genis P, Baldwin T, Schwartz J, LaBenz CJ, Gendelman HE (1995) A regulatory role for astrocytes in HIV-1 encephalitis. An overexpression of eicosanoids, platelet-activating factor, and tumor necrosis factor-alpha by activated HIV-1-infected monocytes is attenuated by primary human astrocytes. J Immunol 154:3567-3581.

O’Donnell T, Rotzinger S, Nakashima TT, Hanstock CC, Ulrich M, Silverstone PH (2000) Chronic lithium and sodium valproate both decrease the concentration of myo-inositol and increase the concentration of inositol monophosphates in rat brain. Brain Res 880:84-91.

Persidsky Y, Limoges J, McComb R, Bock P, Baldwin T, Tyor W, Patil A, Nottet HS, Epstein L, Gelbard H, Flanagan E, Reinhard J, Pirruccello SJ, Gendelman HE (1996) Human immunodeficiency virus encephalitis in SCID mice. Am J Pathol 149:1027-1053.

Persidsky Y, Buttini M, Limoges J, Bock P, Gendelman HE (1997) An analysis of HIV-1-associated inflammatory products in brain tissue of humans and SCID mice with HIV-1 encephalitis. J Neurovirol 3:401-416.

Sinha D, Wang Z, Ruchalski KL, Levine JS, Krishnan S, Lieberthal W, Schwartz JH, Borkan SC (2005) Lithium activates the Wnt and phosphatidylinositol 3-kinase Akt signaling pathways to promote cell survival in the absence of soluble survival factors. Am J Physiol Renal Physiol 288:F703-F713.

Song L, Zhou T, Jope RS (2004) Lithium facilitates apoptotic signaling induced by activation of the Fas death domain-containing receptor. BMC Neurosci 5:20.

Stambolic V, Ruel L, Woodgett JR (1996) Lithium inhibits glycogen synthase kinase- 3 activity and mimics wingless signalling in intact cells. Curr Biol 6:1664-1668.

Stanley LC, Mrak RE, Woody RC, Perrot LJ, Zhang S, Marshak DR, Nelson SJ, Griffin WS (1994) Glial cytokines as neuropathogenic factors in HIV infection: pathogenic similarities to Alzheimer's disease. J Neuropathol Exp Neurol 53:231-238.

Tong N, Sanchez JF, Maggirwar SB, Ramirez SH, Guo H, Dewhurst S, Gelbard HA (2001) Activation of glycogen synthase kinase 3 beta (GSK-3beta) by platelet activating factor mediates migration and cell death in cerebellar granule neurons. Eur J Neurosci 13:1913-1922.

Tyson DR, Swarthout JT, Jefcoat SC, Partridge NC (2002) PTH induction of transcriptional activity of the cAMP response element-binding protein requires the serine 129 site and glycogen synthase kinase-3 activity, but not casein kinase II sites. Endocrinology 143:674-682.

Wilkie FL, Morgan R, Fletcher MA, Blaney N, Baum M, Komaroff E, Szapocznik J, Eisdorfer C (1992) Cognition and immune function in HIV-1 infection. AIDS 6:977-981.

Williams RS, Cheng L, Mudge AW, Harwood AJ (2002) A common mechanism of action for three mood-stabilizing drugs. Nature 417:292-295.

Xiong H, Zeng YC, Zheng J, Thylin M, Gendelman HE (1999) Soluble HIV-1 infected macrophage secretory products mediate blockade of longterm potentiation: a mechanism for cognitive dysfunction in HIV-1associated dementia. J Neurovirol 5:519-528.

Xiong H, Boyle J, Winkelbauer M, Gorantla S, Zheng J, Ghorpade A, Persidsky Y, Carlson KA, Gendelman HE (2003) Inhibition of long-term potentiation by interleukin-8: implications for human immunodeficiency virus-1-associated dementia. J Neurosci Res 71:600-607.

Zhang F, Phiel CJ, Spece L, Gurvich N, Klein PS (2003) Inhibitory phosphorylation of glycogen synthase kinase-3 (GSK-3) in response to lithium. Evidence for autoregulation of GSK-3. J Biol Chem 278:33067-33077.

Zink WE, Zheng J, Persidsky Y, Poluektova L, Gendelman HE (1999) The neuropathogenesis of HIV-1 infection. FEMS Immunol Med Microbiol 26:233-241.

Zink WE, Anderson E, Boyle J, Hock L, Rodriguez-Sierra J, Xiong H, Gendelman HE, Persidsky Y (2002) Impaired spatial cognition and synaptic potentiation in a murine model of human immunodeficiency virus type 1 encephalitis. J Neurosci 22:2096-2105.

Zorrilla Zubilete M (2003) Mechanism of action of lithium: intracellular signaling pathways. Vertex 14:45-52. 